\title{
Investigating the relationships among lung function variables in chronic obstructive pulmonary disease in men
}

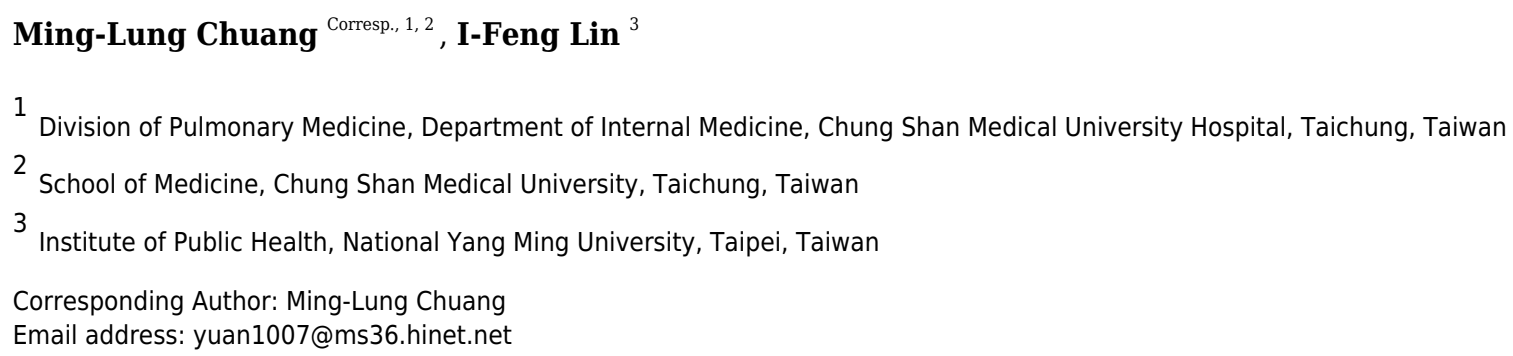

Background: In patients with chronic obstructive pulmonary disease (COPD), the independent contributions of individual lung function variables to outcomes may be lower when they are modelled together if they are collinear. In addition, lung volume measurements may not be necessary after spirometry data have been obtained. However, these hypotheses depend on whether forced vital capacity (FVC) can predict total lung capacity (TLC). Moreover, the definitions of hyperinflation and air trapping according to lung function variables overlap and need be clarified. Therefore, the aim of this study was to evaluate the relationships among various lung function parameters to elucidate these issues. Methods: Demographic data and 26 parameters of full lung function were measured in 94 men with COPD and analyzed using factor and correlation analyses. Results: Factor analysis revealed five latent factors. Inspiratory capacity (IC)/TLC and residual volume (RV)/TLC were most strongly correlated with all other lung volumes. IC/TLC, RV/TLC, and functional residual capacity (FRC)/TLC were collinear and were potential markers of air trapping, whereas TLC\%, $\mathrm{FRC} \%$, and $\mathrm{RV} \%$ were collinear and were potential markers of hyperinflation. RV/TLC $>0.4$ (or IC/TLC $<0.4$ ) was comparable with the ratio of forced expiratory volume in one second $\left(\mathrm{FEV}_{1}\right)$ and $\mathrm{FVC}<0.7$. FVC\% and $\mathrm{FEV}_{1} \%$ were poorly correlated with TLC\%. The correlation study showed that TLC\%, RV/TLC, and $\mathrm{FEV}_{1} \%$ could be used to represent individual latent factors for hyperinflation, air trapping, inspiration, expiration, and obstruction. Combined with diffusion capacity\%, these four factors could be used to represent comprehensive lung function. Conclusions: This study identified collinear relationships among individual lung function variables and thus selecting variables with close relationships for correlation studies should be performed with caution. This study also differentiated variables for air trapping and lung hyperinflation. Lung volume measurements are still required even when spirometry data are available. Four out of 26 lung function variables from individual latent factors could be 
used to concisely represent lung function. 


\section{Investigating the Relationships among Lung Function Variables in Chronic} 2 Obstructive Pulmonary Disease in Men

3

4 Ming-Lung Chuang, M.D. ${ }^{1,2}$, I-Feng Lin, Dr.P.H. ${ }^{3}$

$5 \quad{ }^{1}$ Division of Pulmonary Medicine and Department of Internal Medicine, Chung Shan Medical

6 University Hospital, Taichung, Taiwan, R.O.C.

$7 \quad{ }^{2}$ School of Medicine, Chung Shan Medical University, Taichung, Taiwan, R.O.C.

8 'Institute of Public Health, National Yang Ming University, Taipei, Taiwan, R.O.C.

10 Correspondence to:

11 Ming-Lung Chuang, M.D.

12 Division of Pulmonary Medicine

13 Department of Internal Medicine

14 Chung Shan Medical University Hospital

15 Tel: +886-4-2473-9595 ext. 34718

16 E-mail: yuan1007@ms36.hinet.net

17

18 Running title: Relationship among lung function variables in COPD

19 Registered at this site: Chung Shan Medical University Hospital, Taichung, Taiwan

20 Registration number: CSH-2012-C-23 and CSH-2019-C-30

21 The name of the institution(s) review board: The Institutional Review Board of Chung Shan

22 Medical University Hospital 


\section{Abstract}

25 Background: In patients with chronic obstructive pulmonary disease (COPD), the independent contributions of individual lung function variables to outcomes may be lower when they are modelled together if they are collinear. In addition, lung volume measurements may not be necessary after spirometry data have been obtained. However, these hypotheses depend on whether forced vital capacity (FVC) can predict total lung capacity (TLC). Moreover, the definitions of hyperinflation and air trapping according to lung function variables overlap and need be clarified. Therefore, the aim of this study was to evaluate the relationships among various lung function parameters to elucidate these issues.

33 Methods: Demographic data and 26 parameters of full lung function were measured in 94 men

34 with COPD and analyzed using factor and correlation analyses.

35 Results: Factor analysis revealed five latent factors. Inspiratory capacity (IC)/TLC and residual

36 volume $(\mathrm{RV}) / \mathrm{TLC}$ were most strongly correlated with all other lung volumes. IC/TLC, RV/TLC,

37 and functional residual capacity (FRC)/TLC were collinear and were potential markers of air

38 trapping, whereas $\mathrm{TLC} \%, \mathrm{FRC} \%$, and $\mathrm{RV} \%$ were collinear and were potential markers of

39 hyperinflation. $\mathrm{RV} / \mathrm{TLC}>0.4$ (or IC/TLC $<0.4$ ) was comparable with the ratio of forced

40 expiratory volume in one second $\left(\mathrm{FEV}_{1}\right)$ and $\mathrm{FVC}<0.7 . \mathrm{FVC} \%$ and $\mathrm{FEV}_{1} \%$ were poorly

41 correlated with TLC $\%$. The correlation study showed that TLC $\%$, RV/TLC, and FEV $\%$ could 
42 be used to represent individual latent factors for hyperinflation, air trapping, inspiration,

43 expiration, and obstruction. Combined with diffusion capacity $\%$, these four factors could be used

44 to represent comprehensive lung function.

45 Conclusions: This study identified collinear relationships among individual lung function

46 variables and thus selecting variables with close relationships for correlation studies should

47 be performed with caution. This study also differentiated variables for air trapping and lung

48 hyperinflation. Lung volume measurements are still required even when spirometry data are

49 available. Four out of 26 lung function variables from individual latent factors could be used to

50 concisely represent lung function. 


\section{INTRODUCTION}

53 Lung function variables including residual volume (RV)/total lung capacity (TLC),

54 inspiratory capacity (IC)/TLC, RV\% predicted and forced expiratory volume in one second

55 percentage predicted ( $\mathrm{FEV}_{1} \%$ )have been reported to be well correlated with the outcomes of

56 patients with chronic obstructive pulmonary disease (COPD) including physiological

57 deterioration, dyspnea, exercise intolerance, acute exacerbations, and mortality (O'Donnell et al.,

2001; Nishimura et al., 2002; Casanova et al., 2005; Tantucci et al., 2008; Vassaux et al., 2008;

Zhang et al., 2013; Chuang et al., 2015; Shin et al., 2015). Correlations between lung function

variables and outcomes have been reported sporadically, such as associations between IC/TLC important to investigate the relationships among lung function variables. 
70 combined with ratios of functional residual capacity (FRC), IC or RV and TLC (Ruppel 1991;

71 Gagnon et al., 2014; Cohen 2017; Vaz Fragoso et al., 2017). However, these definitions are

72 unclear and arbitrary and understanding the relationships among these variables may improve the

73 definitions.

74 It has also been reported that TLC measurements are not necessary after spirometry data

75 have been obtained. However, this will not be the case if forced vital capacity (FVC) cannot

76 predict TLC, as obstructive ventilatory impairment may be combined with restriction in patients

77 with COPD (Dykstra et al., 1999; Nishimura et al., 2002; Calverley et al., 2005; Deesomchok et

78 al., 2010; Labbé et al., 2010; Shin et al., 2015). To resolve these three issues, this study aimed to

79 thoroughly evaluate the relationships among lung function parameters using factor and

80 correlation analyses.

\section{METHODS}

\section{Study Design}

83 In this observational cross-sectional study, we analyzed lung function data from participants

84 with COPD at Chung Shan Medical University Hospital. A total of 26 lung volume and capacity

85 parameters were expressed in liters, \%predicted, and ratio of TLC, FVC and SVC (Appendix 1).

86 The Chung Shan Medical University Hospital Institutional Review Board (CS11144 and

87 CS19014) approved this study, which was conducted in compliance with the Declaration of 
88 Helsinki.

89 Participants

90 The diagnosis of COPD was made by board-certified pulmonologists according to the

91 GOLD criteria.(GOLD Committees 2017) Participants with other thoracic diseases such as

92 pleural diseases or thoracic cage disorders were excluded from this study. (GOLD Committees

93 2017) As few female participants meet the COPD criteria in Taiwan (e.g., 4\% according to one

94 study (Huang et al., 2018)), they were excluded from this study. Male adult participants with a

95 post-bronchodilator $\mathrm{FEV}_{1} / \mathrm{FVC}$ of $<0.7$ (GOLD Committees 2017) or 0.7-0.8 with a definite

96 obstructive pattern in spirometry were enrolled (Johns et al., 2014). The latter definition was

97 used for two reasons. First, extensive small airway disease can exist before it is detectable with a

$98 \mathrm{FEV}_{1} / \mathrm{FVC}<0.7$, and thus the concavity of expiratory flow-volume curve was considered (Johns

99 et al., 2014). Second, some participants with increased small airway compressibility had a

100 preserved $\mathrm{FEV}_{1} / \mathrm{FVC}$ but a reduced $\mathrm{FEV}_{1} /$ slow VC ratio (Johns et al., 2014; Saint-Pierre et al.,

1012019 (in press)). The exclusion criteria included $\mathrm{FEV}_{1} / \mathrm{FVC}$ of $0.7-0.8$ with an equivocal

102 obstructive pattern or with a significant post-bronchodilator effect, i.e., increase in $\mathrm{FEV}_{1}$ of

$103>12 \%$ and $200 \mathrm{~mL}$ from baseline (GINA Committees 2017) or bronchial asthma (GINA

104 Committees 2017) diagnosed by the board-certified pulmonologists. Bronchial asthma was

105 excluded because the proportion of lung subdivisions is different in these two diseases (Dykstra 
106 et al., 1999). Informed consent was obtained from each participant by them signing the consent

107 form.

\section{Measurements}

109 Pulmonary function testing. Cigarette smoking, drinking coffee, tea, or alcohol, and taking

110 medications were not permitted 24 hours before any test. Bronchodilators were not administered

111 within 3 hours for short-acting beta agonists and 12 hours for long-acting beta agonists before

112 the tests. $\mathrm{FEV}_{1}, \mathrm{TLC}$, and RV were measured using spirometry and body plethysmography

113 (MasterScreen ${ }^{\mathrm{TM}}$ Body, Carefusion, Wuerzburg, Germany) in accordance with the currently

114 recommended standards.(Miller et al., 2005; Wanger et al., 2005) The best of three technically

115 satisfactory readings was used.(ATS/ERS 2002; Miller et al., 2005; Miller et al., 2005) All of the

116 spirometry data were obtained before and after inhaling $400 \mu \mathrm{g}$ of fenoterol $\mathrm{HCl}$. Post-dose

117 measurements were performed 15 minutes after inhalation. Static lung volume data and diffusing

118 capacity for carbon monoxide $\left(\mathrm{D}_{\mathrm{L}} \mathrm{CO}\right)$ data measured using the single-breath technique were

119 obtained before inhaling fenoterol. For details of lung subdivision measurements, please refer to

120 Appendix 2. Simple volume calibration was conducted using a 3-L syringe before each test.

121 Accuracy checks for body plethysmograph mouth flow and pressure and box pressure were

122 conducted daily. We have previously reported the predicted values currently used at our institute.

123 The predicted values are in line with our previous report (Chuang et al., 2001). The reason that 
124 we did not use lower limit of normal as the criterion of airflow limitation was that we did not

125 have reference equations using post-bronchodilator $\mathrm{FEV}_{1}$ and $\mathrm{FVC}$ for the Taiwanese population.

\section{Statistical Analysis}

128 All of the data were checked for normal distribution by the Kolmogorov-Smirnov test. Data were

129 summarized as mean \pm standard deviation or median $\left(25^{\text {th }}-75^{\text {th }}\right.$ percentiles $)$ when appropriate.

130 We used factor analysis to evaluate the correlated pulmonary function variables and identify the

131 latent factors. We extracted the initial set of factors using the principal-component method based

132 on Kaiser criterion, then 1-more and 1-fewer factor models were also evaluated. The factors were

133 then rotated using an orthogonal transformation method (VARIMAX in SAS) to assess the

134 interpretability of the factors. The numbers of factors determined in the final model was based on

135 biological plausibility. Pearson's or Spearman's correlation coefficients were further used when

136 appropriate for quantifying the pair-wise relationships among the pulmonary function variables.

137 All statistical analyses were performed using SAS statistical software (SAS Institute Inc., Cary,

138 NC, USA). Statistical significance was set at two-sided $p<0.05$.

140 RESULTS

141 A total of 94 male participants (mean age 68.1 \pm 7.2 years) with COPD were enrolled after 
142 excluding 10 participants (Table 1 and Figure 1). Five of these 10 participants who were

143 excluded were diagnosed with bronchial asthma including three females and another five had

144 spirometry data that did not meet the inclusion criteria. Only five of the 94 participants had a

$145 \mathrm{FEV}_{1} / \mathrm{FVC}$ ratio $0.7-0.8$ with a definite obstructive pattern. Most of the participants had

146 moderate airflow obstruction (Table 1).

147 Up to 26 lung function parameters were presented in absolute values, \%predicted, and as the

148 ratio of lung volume or capacity and TLC or FVC for each patient. In normal participants, lung

149 volume in liters was closely related to body height, gender, and age and hence it was usually

150 presented with \%predicted. Therefore, the following variables were omitted from correlation

151 analysis: TLC, FRC, IC, IRV, ERV, RV, FVC, SVC, and FEV ${ }_{1}$ in liters and $\mathrm{D}_{\mathrm{L}} \mathrm{CO}$ in

$152 \mathrm{~mL} / \mathrm{min} / \mathrm{mmHg}$.

153 Factor analysis. A preliminary model with four factors were selected by Kaiser criterion and

154 then the 3-factor and 5-factor models were also evaluated. The five latent factor model was

155 identified according to biological plausibility and this model explained $92 \%$ of total variation

156 (Table 2). The communalities were generally high ( 12 of 16 were $>0.9$, three were between 0.75

157 and 0.9 , and only one was 0.4 ). Factor 1 was highly related to inspiration and moderately to air

158 trapping; factor 2 was highly related to lung volumes and moderately to air trapping; factor 3 was

159 highly related to expiration and moderately to air trapping; factor 4 was highly related to airflow 
160 obstruction; and factor 5 was highly related to diffusion capacity.

161 Pearson's or Spearman's correlation coefficients for lung volume subdivisions. Individual

162 variables involving \%predicted were strongly correlated with each corresponding variable in ratio

163 of TLC (Table 3, all $\mathrm{r}^{2}=0.38-0.85$, all $\mathrm{p}<0.0001$ ). TLC $\%$, FRC $\%$, and RV\% were highly

164 correlated $\left(\mathrm{r}^{2}=0.59-0.74\right) . \mathrm{RV} \%$ was the best single parameter correlated with $\mathrm{D}_{\mathrm{L}} \mathrm{CO} \%$, although

165 only with a negative moderate correlation $\left(\mathrm{r}^{2}=0.22, \mathrm{p}<0.0001\right)$. FRC/TLC and IC/TLC were

166 reciprocal $\left(\mathrm{r}^{2}=0.98\right)$ and highly correlated with $\mathrm{RV} / \mathrm{TLC}\left(\mathrm{r}^{2}=0.37-0.38\right)$, and were most frequently

167 correlated with all of the other lung subdivisions in \%predicted and ratio of TLC. IC\% and IRV\%

168 were approximately collinear $\left(r^{2}=0.9\right)$. All $r^{2}$, the coefficient of determination for Pearson's

169 correlations, indicated the proportion of variance in one variable explained by variation in the

170 other.

171 Pearson's or Spearman's correlation coefficients for spirometry variables. FVC\% and SVC\%

172 were highly correlated with $\mathrm{FEV}_{1} \%\left(\mathrm{r}^{2}=0.38-0.74\right.$, Table 4); however, they were not correlated

173 with $\mathrm{FEV}_{1} / \mathrm{FVC}\left(\mathrm{r}^{2}=0.00-0.00\right)$. Interestingly, $\mathrm{FEV}_{1} \%$ and $\mathrm{FEV}_{1} / \mathrm{FVC}$ were related $\left(\mathrm{r}^{2}=0.4\right)$.

174 Pearson's or Spearman's correlation coefficients between spirometry and lung volume

175 subdivisions. FVC\% and $\mathrm{FEV}_{1} \%$ were modestly or not correlated with TLC\% (Table 4, $\mathrm{r}^{2}=0.01$ -

176 0.04) despite being correlated with most of the subdivisions in \%predicted and ratio of TLC. Of

17789 participants with $\mathrm{FEV}_{1} / \mathrm{FVC}<0.7,81$ (91\%) had IC/TLC $<0.4$ and $85(96 \%)$ had RV/TLC 
$178 \geq 0.4$

179 Based on these results, TLC\%, RV/TLC (or $\mathrm{FEV}_{1} / \mathrm{FVC}$ ), $\mathrm{FEV}_{1} \%$, and $\mathrm{D}_{\mathrm{L}} \mathrm{CO} \%$ were selected

180 from the five factors as representative of lung function.

181

\section{DISCUSSION}

183 Factor analysis and Pearson's or Spearman's correlation coefficients. Factor analysis is a good

184 method to identify unobservable factors from a large number of observed variables, thereby

185 allowing variables to be used to estimate a lower number of latent factors. In this study, we

186 identified five latent factors, i.e., those highly related to inspiration, expiration, lung volumes,

187 airflow obstruction, and diffusion, respectively (Table 2). However, lung volumes and

188 inspiration and expiration volumes were also mixed with air trapping, suggesting that

189 hyperinflation and air trapping overlapped (see below). In further analysis, Pearson's or

190 Spearman's correlation coefficients revealed the lung function variables associated with

191 hyperinflation and air trapping (Table 3).

192 However, it is possible that the small sample size would not meet the usual heuristics for

193 principle component analysis or factor analysis, and that this would mean it was difficult to

194 explain the implications of the non-normality and outliers in the data. Although the sample size

195 of the present study was small at 88 , the influence of the small sample size depends on the data 
196 characteristics. Previous studies have shown that even a small sample size of fewer than 50

197 participants can yield results with small distortions under data conditions of high loading, low

198 number of factors, and high number of variables (de Winter et al., 2009). When communalities

199 are high, the sample size tends to have less influence on the quality of factor solutions than when

200 communalities are low (Hogarty et al., 2005). We only had limited data, however the

201 communalities were generally high ( 12 of 16 were $>0.9$, three were between 0.75 and 0.9 , and

202 only one was 0.4 ) in our final factor model. Spearman's correlation coefficients were applied for

203 the pairs involving non-normality (Tables 3 and 4) and the results were not substantially different

204 from those using the Pearson's correlations. Therefore, we assumed that the potential non-

205 normality might not substantially influence the current results of factor analysis.

206 In addition, one may argue the rationale for using the Kaiser criterion for selecting a

207 preliminary model in this study. While both the Kaiser criterion and parallel analysis use

208 information from eigenvalues of the correlation matrix, the latter can be used to determine more

209 consistently the number of factors, especially in small samples. As appropriate factor retention

210 would depend on biological plausibility rather than purely on statistical consideration, we used

211 the Kaiser criterion to determine the preliminary model, and then selected a five-factor final

212 model (as stated in the previous sections). One of the purposes of this study was to explore

213 different domains (latent factors) related to individual lung function parameters. Rotation makes 
214 latent factors more interpretable. We used VARIMAX, an orthogonal rotation that did not

215 change the communalities, and the total variance explained (still 92\%) while preserving

216 correlations between variables (Rencher et al., 2012).

217 Lung volume subdivisions. It has been frequently reported that both IC/TLC and RV/TLC are

218 related to prognostic, exercise capacity, exertional dyspnea, and dynamic lung expansion in

219 patients with COPD. Similarly, IC/TLC and RV/TLC have been reported to have very similar

220 Harrell's C-statistics in prognosis analysis $(0.81$ and 0.80 , respectively, Table 4 of reference

221 (Shin et al., 2015)). We hypothesize that IC/TLC and RV/TLC have similar Harrell's C-statistics

222 because of their collinearity.

$223 \mathrm{RV} \%$ was the largest and the most frequent responder following bronchodilation in a

224 previous report (Deesomchok et al., 2010). In the present study, it showed the best inverse but

225 moderate correlation of all lung function variables with $\mathrm{D}_{\mathrm{L}} \mathrm{CO} \%$.

226 Definitions of pulmonary hyperinflation and air trapping of the lung are inconsistent in the

227 literature, for example: static hyperinflation = hyperinflation at rest (Gagnon et al., 2014) $=$

228 IC/TLC $<0.25$ (Casanova et al., 2005) = RV/TLC (Nishimura et al., 2002; Budweiser et al.,

229 2014) $\geq 0.4$ (Albuquerque et al., 2006; Shin et al., 2015) or $>0.35$ plus an increased TLC (Ruppel

2301991 ) or $>0.3$ plus RV\% $\geq 120 \%$ (Labbé et al., 2010); air trapping $=\mathrm{RV} / \mathrm{TLC}>0.35$ plus a

231 normal TLC (Ruppel 1991) or RV\% $\geq 120 \%$ (Deesomchok et al., 2010). To some extent, these 
232 definitions overlap RV, IC and TLC and their derivatives. In addition, the relationship between

$233 \mathrm{RV} / \mathrm{TLC}$ and TLC\% is inconsistent in previous reports (Deesomchok et al., 2010; Vaz Fragoso et

234 al., 2017). Despite knowing that factor three involved lung volumes, we further evaluated the

235 relationships among all lung subdivisions with Pearson's or Spearman's correlation, and found

236 that $\mathrm{RV} \%$, FRC $\%$, and TLC \% were highly correlated $\left(\mathrm{r}^{2}=0.59-0.74\right)$, and that RV/TLC,

237 FRC/TLC and IC/TLC were also highly correlated $\left(r^{2}=0.37-0.98\right)$. In contrast, the correlations of

$238 \mathrm{RV} / \mathrm{TLC}, \mathrm{FRC} / \mathrm{TLC}$ and IC/TLC with TLC\% were only $\mathrm{r}^{2}=0.08,0.18$, and 0.20 , respectively.

$239 \mathrm{RV}, \mathrm{FRC}$, and TLC in \%predicted are all related to static lung volume (Gagnon et al., 2014;

240 Vaz Fragoso et al., 2017). RV\% is mainly composed of FRC\%,(Dykstra et al., 1999) and FRC\%

241 is mainly composed of TLC\% in COPD. This is consistent with a previous report in which RV\%

242 was highly correlated with FRC\% ( $\mathrm{r}=0.9)$ (Deesomchok et al., 2010). Therefore, we recommend

243 that $\mathrm{RV} \%, \mathrm{FRC} \%$, and $\mathrm{TLC} \%$ can be used as biomarkers for hyperinflation, and that RV/TLC

244 and IC/TLC (reciprocal FRC/TLC) can be used as biomarkers for air trapping, even though these

245 two types of biomarkers are closely related. It makes sense that the IC/TLC triad is more

246 sensitive than RV\% (Albuquerque et al., 2006; Zhang et al., 2013) and $\mathrm{FEV}_{1} \%$ in relation to

247 exercise capacity, as the IC/TLC triad, $\mathrm{RV} \%$ and $\mathrm{FEV}_{1} \%$ belong to different factors, denoting

248 that air trapping plays a more important role in exercise capacity than hyperinflation and airflow

249 obstruction (Zhang et al., 2013). 
250 Spirometry and lung volume subdivisions. The need for simultaneous measurements of lung

251 volume and spirometry is controversial. $\mathrm{FEV}_{1} / \mathrm{FVC}$, a biomarker of airway obstruction, was

252 significantly correlated with the biomarkers for air trapping and hyperinflation in this study

253 (Table 4). Airway obstruction can easily be assessed using spirometry. Therefore, additional

254 measurements of static lung volume add little to the clinical interpretation. This is consistent

255 with the study by Dykstra et al., in which $87 \%$ of 1,872 patients with reduced vital capacity had a

256 high RV/TLC, and only 10\% had a low TLC\% (Dykstra et al., 1999). This concept was further

257 confirmed in their report as $\mathrm{FEV}_{1} \%$ was reported to predict $\mathrm{RV} \%, \mathrm{RV} / \mathrm{TLC}$, and $\mathrm{TLC} \%(\mathrm{r}=-0.76$,

$258-0.66$ and -0.33 , respectively, all $\mathrm{p}<0.0001$ ) (Dykstra et al., 1999). Another study reported that a

259 low $\mathrm{FVC} \%$ with a low $\mathrm{FEV}_{1} / \mathrm{FVC}$ ratio could be used as a marker of obstructive ventilation with

260 "pseudo-restriction" (Aaron et al., 1999). However, 10\% of the patients in Dykstra's study had a

261 low TLC $\%$, suggesting the coexistence of a mixed type (obstructive-restrictive impairment)

262 (Dykstra et al., 1999). In addition, another study reported that 8\% of asthmatics had restricted

263 ventilation (Miller et al., 2007). Gardner et al. reported that restriction of the lung may interfere

264 with classifying the severity of obstruction in patients with mixed obstructive-restrictive lung

265 disease according to $\mathrm{FEV}_{1} \%$ adjusted for $\mathrm{TLC} \%$. This adjustment resulted in the downgrading of

$26683 \%$ of their patients to a lesser degree of obstruction (Gardner et al., 2011). Aaron et al.

267 reported that a reduced FVC could only predict a reduced TLC by 40-50\% (Aaron et al., 1999). 
268 Moreover, regarding the effect of bronchodilators on COPD, measurements of lung volume

269 response may be superior to those of flow response (Deesomchok et al., 2010; McCartney et al.,

270 2016). Hence, we disagree with the notion that lung volume measurements are not necessary for

271 patients with reduced VC,(Dykstra et al., 1999) as $\mathrm{FVC} \%$ and $\mathrm{FEV}_{1} \%$ were modestly or not

272 correlated with TLC $\%$ in the present $\left(r^{2}=0.04\right.$ and 0.01 , Table 4$)$, and previous studies (Dykstra

273 et al., 1999; McCartney et al., 2016) and were not correlated with expandable lung volumes

274 (Table 4, IC\%, IRV\%, ERV\%, and IRV/TLC and ERV/TLC). The smaller the FEV \%, the larger

275 the RV\% and RV/TLC, even though TLC\% had probably yet to change (Vaz Fragoso et al.,

276 2017).

$277 \quad \mathrm{FEV}_{1} \%$ was also linearly related to IC (Deesomchok et al., 2010) and VC\% (Nishimura et

278 al., 2002; Deesomchok et al., 2010) in this study, as FEV 1 was $0.76 \pm 0.26$ of IC and IC was

$2790.71 \pm 0.20$ of $\mathrm{FVC}$. FVC\%, SVC $\%$, and $\mathrm{FEV}_{1} \%$ were highly correlated in this study but not with

$280 \mathrm{FEV}_{1} / \mathrm{FVC}$, which may be because a reduction in FVC may result in a normal or mildly reduced

$281 \mathrm{FEV}_{1} / \mathrm{FVC}$ due to pseudo-restriction (Saint-Pierre et al., 2019 (in press)).

282 In summary, TLC \% cannot be replaced by FVC\% and RV/TLC is most frequently and most

283 strongly correlated with other lung function variables and consistent with $\mathrm{FEV}_{1} / \mathrm{FVC}$. $\mathrm{FEV}_{1} \%$ is

284 a marker of the severity of COPD. $\mathrm{D}_{\mathrm{L}} \mathrm{CO} \%$ alone represented factor 5 . Although these four

285 variables could be used to represent all 26 full lung function variables, we do not conclude that 
286 the additional variables should not be collected/examined/included in models.

287

288 Study limitations

289 Diagnostic instability of COPD diagnosis has been reported in approximately 20\% and 10\% of

290 individuals with mild and moderate airflow obstruction, respectively, after 4-5 years of follow-up

291 (Aaron et al., 2017). However, most (92\%) of our participants had moderate to very severe

292 airflow obstruction; therefore, we estimated that $6.7 \%$ of our participants probably had

293 diagnostic instability. Selecting an appropriate reference value is important, e.g. TLC or FVC has

294 been reported to be 12\% lower in African Americans than in Caucasians (Lapp et al., 1974). In

295 this study, we arbitrarily reduced the reference values in the literature by $10-15 \%$, as surveillance

296 reports on reference values were unavailable and to consistently follow our previous reports

297 (Chuang et al., 2001). Lung size has been reported to be different between Chinese participants

298 from southern China and northern China, however it is difficult to trace the study participants in

299 Taiwan, as some ancestors came from both northern and southern China. Nevertheless, the use of

300 correlation analysis may have reduced this potential bias. In Guangzhou, China, the estimated

301 prevalence rates of GOLD stage 2 or higher COPD in females and males are approximately 5\%

302 and 10\%, respectively (Mannino et al., 2007). Although we did not have prevalence data of

303 COPD in Taiwan, $96 \%$ of our cohort with COPD were male and only 4\% were female (Huang et 
304 al., 2018). The data from China are quite different from ours, which may be related to the

305 biomass fuel smoke exposure in the Chinese female population (Mannino et al., 2007). Although

306 our study population was small compared to previous reports (Aaron et al., 1999; Dykstra et al.,

307 1999), our patients had COPD alone, whereas previous studies have enrolled COPD patients

308 with various other lung diseases. This may raise concerns that the relationships between lung

309 volumes and their ratios to TLC among the study participants of previous studies may be

310 different from those in our study (Ruppel 2012). In addition, our data were all obtained before

311 bronchodilator inhalation, as pharmacological interventions may alter the relationship between

312 volume and capacity. Hence, the findings of this study should be interpreted with caution when

313 extrapolating to patients after bronchodilator inhalation. Furthermore, only two participants did

314 use ultra-long-acting beta agonists in this study, so that the duration of bronchodilator

315 withdrawal for most of the participants might be appropriate. The relationships among lung

316 function variables in the current study may also have been different if the lung volume and

317 capacity were expressed in a way other than \% predicted. For example, a previous study reported

318 lung volume and capacity were standardized with cubed height or adjusted with multiple linear

319 regression analysis with adjustments for least square mean and adjustments of spirometry with z-

320 scores (Vaz Fragoso et al., 2017). However, these adjustments have not yet been widely used in

321 clinical practice, and further studies are needed to clarify this issue. In the present study, 
$322 \%$ predicted and ratio of lung volume or capacity and TLC or FVC were used instead of using

323 absolute value in liters or $\mathrm{mL} / \mathrm{min} / \mathrm{mmHg}$. This may have reduced confounding caused by body

324 height, sex, and age. In addition, anemia is a factor that should be considered for adjustment

325 when predicting $\mathrm{D}_{\mathrm{L}} \mathrm{CO}$ (Macintyre et al., 2005). However, this may be a minor issue, as the

326 hemoglobin level was $14.4 \pm 1.7 \mathrm{~g} / \mathrm{dL}$ and $83.2 \%$ of our participants had normal hemoglobin levels

$327(\geq 13 \mathrm{~g} / \mathrm{dL})$ and the adjusted coefficient for predicted $\mathrm{D}_{\mathrm{L}} \mathrm{CO}$ was $0.99 \pm 0.05\left(5^{\text {th }}\right.$ percentile $-95^{\text {th }}$

328 percentile: 0.89-1.06). Lastly, COPD has many phenotypes, however we did not specify these

329 phenotypes in this study.

\section{CONCLUSIONS}

331 This study identified several collinear relationships among individual lung function variables

332 Selecting multiple variables with close relationships for correlation studies should be performed

333 with caution. This study also differentiated variables for air trapping and lung hyperinflation.

334 Lung volume measurements are necessary even when spirometry data are available. We

335 identified four of 26 lung function variables from individual latent factors that could be used to

336 concisely represent lung function. 
338 Appendix 1: The 26 lung function variables with their units.

1 TLC, L

2 TLC $\%$ predicted, $\%$

3 FRC, L

$4 \quad \mathrm{FRC} \%$ predicted, $\%$

$5 \mathrm{FRC/TLC}$

$6 \mathrm{RV}, \mathrm{L}$

$7 \quad \mathrm{RV} \%$ predicted, $\%$

8 RV/TLC

9 Expiratory reserve volume, L

10 Expiratory reserve volume, ERV\% predicted, \%

$11 \mathrm{ERV} / \mathrm{TLC}$

$12 \mathrm{IC}, \mathrm{L}$

13 IC\% predicted, $\%$

$14 \mathrm{IC} / \mathrm{TLC}$

15 Inspiratory reserve volume, $\mathrm{L}$

16 Inspiratory reserve volume, IRV\% predicted, \%

17 IRV/TLC

18 Diffusion capacity for cabon monoxide, $\mathrm{D}_{\mathrm{L}} \mathrm{CO}, \mathrm{mL} / \mathrm{min} / \mathrm{mmHg}$

$19 \mathrm{D}_{\mathrm{L}} \mathrm{CO} \%$ predicted, \%

20 Forced vital capacity, FVC, L

21 FVC\% predicted, \%

22 Forced expiratory volume in one second, $\mathrm{FEV}_{1}, \mathrm{~L}$

$23 \mathrm{FEV}_{1} \%$ predicted, $\%$

$24 \mathrm{FEV}_{1} / \mathrm{FVC}$

25 Slow vital capacity, SVC, L

$26 \mathrm{SVC} \%$ predicted, \%

339

340 Appendix 2

341 TLC was defined as IC plus FRC.(Wanger et al., 2005) Thoracic gas volume was measured by

342 panting at a rate of $1 \mathrm{~Hz}$ when the flow was occluded at the end of stable expiration. FRC was 
343 calculated from thoracic gas volume after adjusting for stable tidal volume. IC was measured

344 from the end of stable expiration to the top of TLC as far as possible after panting. $\mathrm{V}_{\mathrm{T}}$ was

345 averaged from several stable breaths at rest, and IRV was measured from IC minus the averaged

$346 \mathrm{~V}_{\mathrm{T}}$. ERV was measured as SVC minus IC, and RV was measured as FRC minus ERV. Predicted

347 IC was calculated as predicted TLC minus predicted FRC, and predicted ERV was calculated as

348 predicted FRC minus predicted RV.(Deesomchok et al., 2010)

349 


\section{Figure Legends}

351

352 Figure 1. Flow diagram. A total of 104 participants with chronic obstructive pulmonary disease

353 were screened. 94 patients were enrolled and analyzed after excluding 10 participants. Of the 94

354 participants, two participants missed the lung volume measurements, and six participants missed

355 diffusing capacity for carbon monoxide. The differences in demographic data and spirometry

356 between the six and 88 participants were not statistically significant except body weight and

357 body mass index $\left(54.5 \pm 3.0 \mathrm{~kg}\right.$ versus $61.7 \pm 9.7 \mathrm{~kg}, \mathrm{p}<0.001$ and $20.9 \pm 1.3 \mathrm{~kg} / \mathrm{m}^{2}$ versus $22.7 \pm 3.2$

$358 \mathrm{~kg} / \mathrm{m}^{2} \mathrm{p}<0.05$, respectively). 
360

361

362

363

364

365

366

367

368

369

370

371

372

373

374

375

376

377

378

379

380

381

382

383

384

385

386

387

388

389

390

391

392

393

394

\section{References}

Aaron, SA, RE Dales, P Cardinal. 1999. How accurate is spirometry at predicting restrictive pulmonary impairment? Chest 115: 869-873

Aaron, SD, WC Tan, J Bourbeau, DD Sin, RH Loves, J MacNeil, GA Whitmore, CRR Network. 2017. Diagnostic Instability and Reversals of Chronic Obstructive Pulmonary Disease Diagnosis in Individuals with Mild to Moderate Airflow Obstruction. Am J Respir Crit Care Med 196: 306-314. DOI 10.1164/rccm.201612-2531OC.

Albuquerque, AL, LE Nery, DS Villaça, TY Machado, CC Oliveira, AT Paes, N J.A. 2006. Inspiratory fraction and exercise impairment in COPD patients GOLD stages II-III. Eur Respir J 28: 939-944. DOI 10.1183/09031936.06.00040506.

ATS/ERS, S. 2002. ATS/ERS Statement on respiratory muscle testing. Am J Respir Crit Care Med 166: 518-624 DOI 10.1164/rccm.166.4.518.

Budweiser, S, M Harlacher, M Pfeifer, RA Jörres. 2014. Co-morbidities and hyperinflation are independent risk factors of all-cause mortality in very severe COPD. COPD 11: 388-400. DOI 10.3109/15412555.2013.836174.

Calverley, PMA, NG Koulouris. 2005. Flow limitation and dynamic hyperinflation: key concepts in modern respiratory physiology. Eur Respir J 25: 186-199. DOI 10.1183/09031936.04.00113204.

Casanova, C, C Cote, JP de Torres, A Aguirre-Jaime, JM Marin, V Pinto-Plata, BR Celli. 2005. Inspiratory-to-total lung capacity ratio predicts mortality in patients with chronic obstructive pulmonary disease. Am J Respir Crit Care Med 171: 591-597. DOI 10.1164/rccm.200407-867OC.

Chuang, ML, SF Huang, CH Su. 2015. Cardiovascular and respiratory dysfunction in chronic obstructive pulmonary disease complicated by impaired peripheral oxygenation. Int $J$ Chron Obstruct Pulmon Dis 10: 329-337 DOI 10.2147/COPD.S7620.

Chuang, ML, IF Lin, K Wasserman. 2001. The body weight-walking distance product as related to lung function, anaerobic threshold and peak $\mathrm{VO}_{2}$ in COPD patients. Respir Med 95 : 618-626 DOI 10.1053/rmed.2001.1115.

Cohen, Z (2017). Pulmonary function testing. Egan's fundamentals of respiratory care. R. M. Kacmarek, J. K. Stoller and A. J. Heuer. St. Louis, Elsevier: 400-427. de Winter, JD, D Dodou, PA Wieringa. 2009. Exploratory Factor Analysis With Small Sample Sizes. Multivariate Behavioral Research 44: 147-181. DOI 10.1080/00273170902794206. Deesomchok, A, KA Webb, L Forkert, YM Lam, D Ofir, D Jensen, DE O'Donnell. 2010. Lung hyperinflation and its reversibility in patients with airway obstruction of varying severity. COPD 7: 428-437 DOI 10.3109/15412555.2010.528087. 
395

396

397

398

399

400

401

402

403

404

405

406

407

408

409

410

411

412

413

414

415

416

417

418

419

420

421

422

423

424

425

426

427

428

429

430

Dykstra, BJ, PD Scanlon, MM Kester, KC Beck, PL Enright. 1999. Lung volumes in 4,774 patients with obstructive lung disease. Chest 115: 68-74

Gagnon, P, JA Guenette, D Langer, L Laviolette, V Mainguy, F Maltais, F Ribeiro, D Saey. 2014. Pathogenesis of hyperinflation in chronic obstructive pulmonary disease. Int J Chron Obstruct Pulmon Dis 9: 187-201 DOI 10.2147/COPD.S38934.

Gardner, ZS, GL Ruppel, DA Kaminsky. 2011. Grading the severity of obstruction in mixed obstructive-restrictive lung disease. Chest 140: 598-603. DOI 10.1378/chest.10-2860.

GINA Committees. 2017. Global Initiative for Asthma (UPDATED 2017) Disclosure forms for GINA Committees are posted on the GINA Website, www.ginasthma.org, : 1-156

GOLD Committees. 2017. Global Strategy for the Diagnosis, Management, and Prevention of Chronic Obstructive Pulmonary Disease (revised 2015). Disclosure forms for GOLD Committees are posted on the GOLD Website, www.goldcopd.org

Hogarty, KY, CV Hines, JD Kromrey, JM Ferron, KR Mumford. 2005. The quality of factor solutions in exploratory factor analysis: the influence of sample size, communality, and overdetermination. Educational and Psychological Measurement 65: 202-226. DOI 10.1177/0013164404267287.

Huang, TH, TR Hsiue, SH Lin, XM Liao, PL Su, CZ Chen. 2018. Comparison of different staging methods for chronic obstructive pulmonary disease in predicting outcomes. Eur Respir J 51: 1700577. DOI 10.1183/13993003.00577-2017.

Johns, DP, JA Walters, EH Walters. 2014. Diagnosis and early detection of COPD using spirometry. J Thorac Dis 6: 1557-1569. DOI 10.3978/j.issn.2072-1439.2014.08.18.

Labbé, G, E Merlin, C Kauffman, JL Fauquert, MC Héraud, A Labbé. 2010. [The role of lung volume measurements by plethysmography in the follow-up of asthma in children]. Rev Mal Respir. 27: 42-48. DOI 10.1016/j.rmr.2009.11.002.

Lapp, NL, HE Amandus, R Hall, WKC Morgan. 1974. Lung volumes and flow rates in black and white subjects. Thorax 29: 185-188

Macintyre, N, RO Crapo, G Viegi, DC Johnson, CP van der Grinten, V Brusasco, F Burgos, R Casaburi, A Coates, P Enright, P Gustafsson, J Hankinson, R Jensen, R McKay, MR Miller, D Navajas, OF Pedersen, R Pellegrino, J Wanger. 2005. Standardisation of the singlebreath determination of carbon monoxide uptake in the lung. Eur Respir J 26: 720-735 DOI 10.1183/09031936.05.00034905.

Mannino, DM, AS Buist. 2007. Global burden of COPD: risk factors, prevalence, and future trends. Lancet 370: 765-773. DOI 10.1016/S0140-6736(07)61380-4.

McCartney, CT, MN Weis, GL Ruppel, RP Nayak. 2016. Residual Volume and Total Lung Capacity to Assess Reversibility in Obstructive Lung Disease. Respir care 61: 1505-1512. DOI 10.4187/respcare.04323. 
431 Miller, A, A Palecki. 2007. Restrictive impairment in patients with asthma. Respir Med 101:

432

433

434

435

436

437

438

439

440

441

442

443

444

445

446

447

448

449

450

451

452

453

454

455

456

457

458

459

460

461

462

463

464

465

466 272-276 DOI 10.1016/j.rmed.2006.05.008.

Miller, MR, R Crapo, J Hankinson, V Brusasco, F Burgos, R Casaburi, A Coates, P Enright, CP van der Grinten, P Gustafsson, R Jensen, DC Johnson, N MacIntyre, R McKay, D Navajas, OF Pedersen, R Pellegrino, G Viegi, J Wanger. 2005. General considerations for lung function testing. Eur Respir J 26: 153-161 DOI 10.1183/09031936.05.00034505.

Miller, MR, J Hankinson, V Brusasco, F Burgos, R Casaburi, A Coates, R Crapo, P Enright, CP van der Grinten, P Gustafsson, R Jensen, DC Johnson, N MacIntyre, R McKay, D Navajas, OF Pedersen, R Pellegrino, G Viegi, J Wanger. 2005. Standardisation of spirometry. Eur Respir J 26: 319-338 DOI 10.1183/09031936.05.00034805.

Nishimura, K, T Izumi, M Tsukino, T Oga. 2002. Dyspnea is a better predictor of 5-year survival than airway obstruction in patients with COPD. Chest 121: 1434-1440. PMID: 12006425.

O'Donnell, DE, SM Revill, KA Webb. 2001. Dynamic hyperinflation and exercise intolerance in chronic obstructive pulmonary disease. Am J Respir Crit Care Med 164: 770-777 DOI 10.1164/ajrccm.164.5.2012122.

Rencher, AC, WF Christensen (2012). Methods of multivariate analysis., A John Wiley \& Sons, Inc., Publication.

Ruppel, GL (1991). Lung volume tests. Manual of pulmonary function testing. G. L. Ruppel. St. Louis, Mosby Year Book: 1-22.

Ruppel, GL. 2012. What is the clinical value of lung volumes? Respir Care 57: 26-35 DOI $10.4187 /$ respcare. 01374 .

Saint-Pierre, M, J Ladha, DC Berton, G Reimaoa, G Castellia, M Marillier, A Bernard, DE O'Donnell, JA Neder. 2019 (in press). Is the Slow Vital Capacity Clinically Useful to Uncover Airflow Limitation in Subjects With Preserved FEV ${ }_{1} / \mathrm{FVC}$ Ratio? Chest pii: S0012-3692(19)30143-6 DOI 10.1016/j.chest.2019.02.001.

Shin, TR, YM Oh, JH Park, KS Lee, S Oh, DR Kang, S Sheen, JB Seo, KH Yoo, JH Lee, TH Kim, SY Lim, HI Yoon, CK Rhee, KH Choe, JS Lee, SD Lee. 2015. The Prognostic Value of Residual Volume/Total Lung Capacity in Patients with Chronic Obstructive Pulmonary Disease. J Korean Med Soc 30: 1459-1465. DOI 10.3346/jkms.2015.30.10.1459.

Tantucci, C, P Donati, F Nicosia, E Bertella, S Redolfi, M De Vecchi, L Corda, V Grassi, R Zulli. 2008. Inspiratory capacity predicts mortality in patients with chronic obstructive pulmonary disease. Respir Med 102: 613-619. DOI 10.1016/j.rmed.2007.11.004.

Vassaux, C, L Torre-Bouscoulet, S Zeineldine, F Cortopassi, H Paz-Diaz, BR Celli, VM PintoPlata. 2008. Effects of hyperinflation on the oxygen pulse as a marker of cardiac performance in COPD. Eur Respir J 32: 1275-1282 DOI 10.1183/09031936.00151707. Vaz Fragoso, CA, HC Cain, R Casaburi, PJ Lee, L Iannone, LS Leo-Summers, PH Van Ness. 
467 2017. Spirometry, Static Lung Volumes, and Diffusing Capacity. Respir Care 62: 1137468 1147. DOI 10.4187/respcare.05515.

469 Wanger, J, JL Clausen, A Coates, OF Pedersen, V Brusasco, F Burgos, R Casaburi, R Crapo, P 470 Enright, CP van der Grinten, P Gustafsson, J Hankinson, R Jensen, D Johnson, N

471 Macintyre, R McKay, MR Miller, D Navajas, R Pellegrino, G Viegi. 2005. Standardisation 472 of the measurement of lung volumes. Eur Respir J 26: 511-522 DOI

$473 \quad 10.1183 / 09031936.05 .00035005$.

474 Zhang, Y, XG Sun, WL Yang, XY Tan, JM Liu. 2013. Inspiratory fraction correlates with 475 exercise capacity in patients with stable moderate to severe COPD. Respir Care 58: 1923476 1930. DOI 10.4187/respcare.01927. 


\section{Figure 1}

Flow diagram.

A total of 104 participants with chronic obstructive pulmonary disease were screened. 94 patients were enrolled and analyzed after excluding 10 participants. Of the 94 participants, two participants missed the lung volume measurements, and six participants missed diffusing capacity for carbon monoxide. The differences in demographic data and spirometry between the six and 88 participants were not statistically significant except body weight and body mass index $\left(54.5 \pm 3.0 \mathrm{~kg}\right.$ versus $61.7 \pm 9.7 \mathrm{~kg}, \mathrm{p}<0.001$ and $20.9 \pm 1.3 \mathrm{~kg} / \mathrm{m}^{2}$ versus $22.7 \pm 3.2 \mathrm{~kg} / \mathrm{m}^{2} \mathrm{p}<0.05$, respectively) 


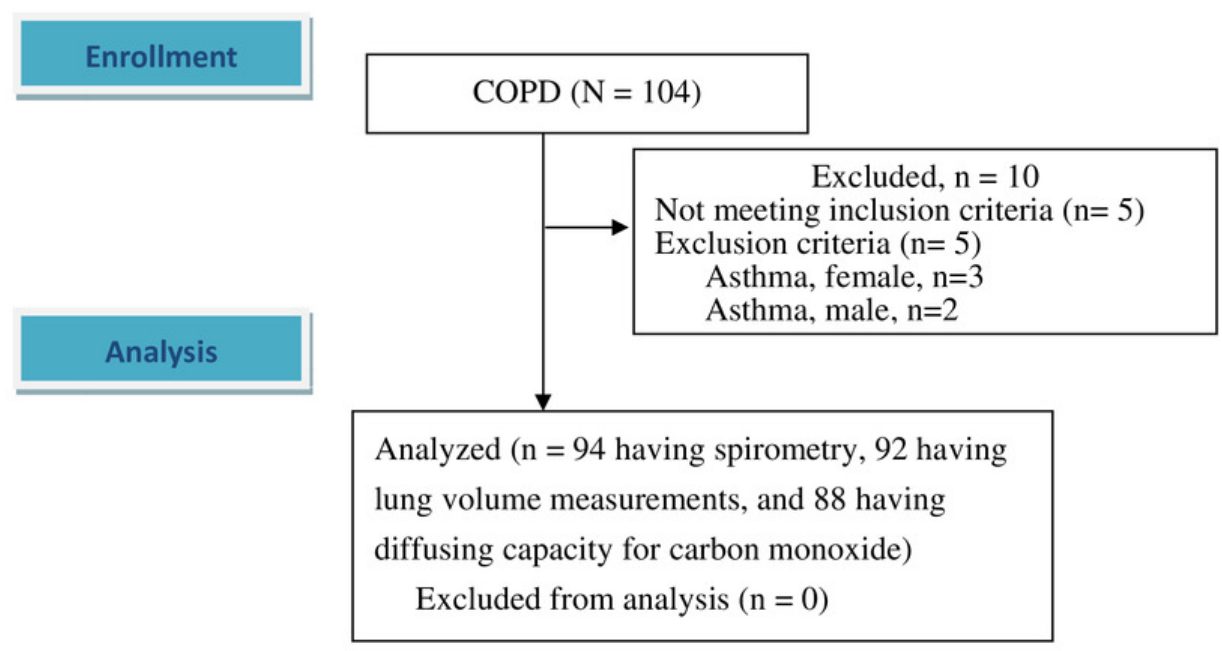




\section{Table $\mathbf{1}$ (on next page)}

Demographics and lung function in 94 participants with chronic obstructive pulmonary disease.

TLC: total lung capacity, L: liter, FRC: functional residual capacity, RV: residual volume, IC: inspiratory capacity, $D_{L} C O$ : diffusing capacity for carbon monoxide, FVC: forced vital capacity, $\mathrm{FEV}_{1}$ : forced expired volume in one second, SVC: slow vital capacity. ${ }^{\dagger} n=92,{ }^{\ddagger} n=88,{ }^{9} n=91, *$ ( GOLD Committees 2017$)$, "\# median $\left(25^{\text {th }}-75^{\text {th }}\right.$ percentiles). 
1 Table 1. Demographics and lung function in 94 participants with chronic obstructive pulmonary 2 disease.

\begin{tabular}{|c|c|c|}
\hline & mean & SD \\
\hline Age, years & 68.1 & 7.2 \\
\hline Height, $\mathrm{cm}$ & 164.5 & 5.8 \\
\hline Weight, $\mathrm{kg}$ & 61.3 & 9.6 \\
\hline Body mass index, $\mathrm{kg} / \mathrm{m}^{2}$ & 22.6 & 3.2 \\
\hline Cigarette smoket, pack.year & 45 & $35.5-60^{\#}$ \\
\hline TLC $\%$ predicted ${ }^{\dagger}, \%$ & 116 & $103-137^{\#}$ \\
\hline FRC $\%$ predicted ${ }^{\dagger}, \%$ & 143 & 35 \\
\hline FRC/TLC ${ }^{\dagger}$ & 0.71 & 0.08 \\
\hline $\mathrm{RV} \%$ predicted ${ }^{\dagger}, \%$ & 170 & 55 \\
\hline $\mathrm{RV} / \mathrm{TLC}^{\dagger}$ & 0.56 & 0.09 \\
\hline Expiratory reserve volume, ERV\% predicted $\%$ & 82 & $55-121^{\#}$ \\
\hline $\mathrm{ERV} / \mathrm{TLC}^{\dagger}$ & 0.15 & 0.08 \\
\hline IC\% predicted ${ }^{\dagger}, \%$ & 87 & 26 \\
\hline $\mathrm{IC} / \mathrm{TLC}^{\dagger}$ & 0.29 & 0.08 \\
\hline Inspiratory reserve volume, IRV\% predicted ${ }^{\dagger}, \%$ & 78 & 47 \\
\hline $\mathrm{IRV}^{\mathrm{TLC}}{ }^{\dagger}$ & 0.15 & 0.09 \\
\hline $\mathrm{D}_{\mathrm{L}} \mathrm{CO} \%$ predicted, $\%$, unadjusted for Hemoglobin $\ddagger$ & 76 & 26 \\
\hline FVC $\%$ predicted, $\%$ & 83 & 22 \\
\hline $\mathrm{FEV}_{1} \%$ predicted, $\%$ & 54 & 19 \\
\hline Mild, $\mathrm{FEV}_{1} \% \geq 80 \% *$, n, $\%$ & $8(9)$ & \\
\hline Moderate, $50 \% \leq \mathrm{FEV}_{1} \%<80 \% *$, n, $\%$ & $47(50)$ & \\
\hline Severe, $30 \% \leq \mathrm{FEV}_{1} \%<50 \% *$, n, $\%$ & $30(32)$ & \\
\hline Very severe, $\mathrm{FEV}_{1} \%<30 \% *$, n, $\%$ & $9(10)$ & \\
\hline $\mathrm{FEV}_{1} / \mathrm{FVC}$ & 0.51 & 0.12 \\
\hline SVC\% predicted", \% & 82 & $70-107^{\#}$ \\
\hline
\end{tabular}

3 TLC: total lung capacity, L: liter, FRC: functional residual capacity, RV: residual volume, IC:

4 inspiratory capacity, $\mathrm{D}_{\mathrm{L}} \mathrm{CO}$ : diffusing capacity for carbon monoxide, $\mathrm{FVC}$ : forced vital capacity,

$5 \quad \mathrm{FEV}_{1}$ : forced expired volume in one second, SVC: slow vital capacity. ${ }^{\mathrm{n}} \mathrm{n}=92, \mathrm{n}=88,{ }^{\mathrm{N}} \mathrm{n}=91$, $6 *$ (GOLD Committees 2017$)$, ${ }^{*}$ median $\left(25^{\text {th }}-75^{\text {th }}\right.$ percentiles $)$. 


\section{Table 2 (on next page)}

Factor analysis showing rotated component matrix ${ }^{\mathrm{a}}$

For all abbreviations, please refer to Table 1. Extraction method: Principal component analysis. Rotation method: Varimax with Kaiser normalization. ${ }^{2}$ Rotation converged in 5 iterations. Bolded number indicating the important variables (arbitrarily defined as value $>0.85$ ) in that factor, Italic number indicating the variables with moderate importance (arbitrarily defined as value $>0.5$ ) in that factor. 
Table 2. Factor analysis showing rotated component matrix ${ }^{\mathrm{a}}$

\begin{tabular}{|l|r|r|r|r|r|}
\hline & \multicolumn{5}{|c|}{ Factors } \\
\cline { 2 - 6 } & \multicolumn{1}{|c|}{1} & 2 & 3 & 4 & \multicolumn{1}{c|}{5} \\
\hline TLC\%p & 0.27 & $\mathbf{0 . 9 3}$ & 0.17 & -0.1 & -0.1 \\
FRC\%p & -0.2 & $\mathbf{0 . 9 4}$ & 0.11 & -0.13 & -0.08 \\
FRC/TLC & -0.68 & 0.65 & 0.1 & -0.21 & -0.07 \\
RV\%p & -0.07 & $\mathbf{0 . 8 9}$ & -0.32 & -0.13 & -0.16 \\
RV/TLC & -0.39 & 0.53 & -0.67 & -0.16 & -0.14 \\
IC\%p & $\mathbf{0 . 9 6}$ & .011 & 0.08 & 0.09 & -0.03 \\
IC/TLC & 0.67 & -0.66 & -0.1 & 0.21 & 0.04 \\
IRV\%p & $\mathbf{0 . 9 4}$ & 0.07 & 0.1 & 0.01 & -0.03 \\
IRV/TLC & $\mathbf{0 . 8 6}$ & -0.19 & 0.03 & -0.01 & 0.13 \\
ERV\%p & -0.18 & 0.22 & $\mathbf{0 . 9 1}$ & -0.04 & 0.14 \\
ERV/TLC & -0.24 & 0.02 & $\mathbf{0 . 9 1}$ & -0.03 & 0.09 \\
D $_{\mathrm{L}}$ CO\%p & 0.07 & -0.25 & 0.19 & 0.18 & $\mathbf{0 . 9 2}$ \\
FVC\%p & 0.48 & -0.09 & 0.76 & 0.12 & -0.04 \\
FEV $\% p$ & 0.37 & -0.26 & 0.54 & 0.65 & 0.06 \\
FEV $/$ FVC & -0.00 & -0.22 & -0.04 & $\mathbf{0 . 9 4}$ & 0.15 \\
SVC\%p & 0.57 & 0.06 & 0.77 & 0.08 & 0.04 \\
\hline
\end{tabular}

1 For all abbreviations, please refer to Table 1. Extraction method: Principal component analysis.

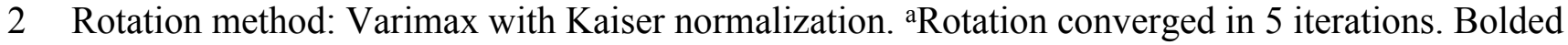
3 number indicating the important variables (arbitrarily defined as value $>0.85$ ) in that factor, Italic 4 number indicating the variables with moderate importance (arbitrarily defined as value $>0.5$ ) in 5 that factor. 


\section{Table 3 (on next page)}

Pearson Correlations ( $r$ ) Pair-Wise Deletion between lung volumes in 92* participants with obstructive airway disease.

TLC: total lung capacity, FRC: functional residual capacity, RV: residual volume, ERV:

expiratory reserve volume, IC: inspiratory capacity, IRV: inspiratory reserve volume, $D_{L} C O$ : diffusing capacity for carbon monoxide. \%: \% predicted. "Spearman correlation coefficient, ${ }^{\S} \mathrm{p}$ $<0.0001,{ }^{\dagger} p<0.001,{ }^{* *} p<0.01$, and ${ }^{*} p<0.05$. NS = non-significant. *Two of 94 participants missed lung volume measurements. 
Table 3. Pearson Correlations (r) Pair-Wise Deletion between lung volumes in $92 *$ participants with obstructive airway disease.

\begin{tabular}{|c|c|c|c|c|c|c|c|c|c|c|c|c|}
\hline & $\mathrm{TLC} \% \#$ & $\mathrm{FRC} \%$ & FRC/TLC & $\mathrm{RV} \%$ & $\mathrm{RV} / \mathrm{TLC}$ & ERV\% \% & ERV/TLC & $\mathrm{IC} \%$ & $\mathrm{IC} / \mathrm{TLC}$ & IRV\% & IRV/TLC & $\mathrm{D}_{\mathrm{L}} \mathrm{CO} \%$ \\
\hline TLC $\%{ }^{\#}$ & & $0.86^{\S}$ & $0.44^{\S}$ & $0.77 \S$ & $0.26^{* *}$ & $-0.27^{* *}$ & NS & $0.33^{* *}$ & $-0.46^{\S}$ & $0.41^{\S}$ & NS & $-0.28^{* *}$ \\
\hline FRC $\%$ & & & $0.75^{\S}$ & $0.87 \S$ & $0.52 \S$ & $0.32^{* *}$ & NS & NS & $-0.76^{\S}$ & NS & $-0.28^{* *}$ & $-0.34^{* *}$ \\
\hline FRC/TLC & & & & $0.62^{\S}$ & $0.62^{\S}$ & $0.29^{* *}$ & $0.29^{* *}$ & $-0.63^{\S}$ & $-0.99^{\S}$ & $-0.53^{\S}$ & $-0.65^{\S}$ & $-0.29^{* *}$ \\
\hline RV\% & & & & & $0.71^{\S}$ & NS & $-0.23^{*}$ & NS & $-0.63 \S$ & NS & $-0.22^{*}$ & $-0.47 \S$ \\
\hline RV/TLC & & & & & & $-0.45^{\S}$ & $-0.57 \S$ & $-0.44^{\S}$ & $-0.61^{\S}$ & $-0.38^{(5)}$ & $-0.51^{\S}$ & $-0.43^{\S}$ \\
\hline ERV\%\# & & & & & & & $0.92^{\S}$ & NS & $-0.3^{* *}$ & NS & NS & NS \\
\hline ERV/TLC & & & & & & & & NS & $-0.27^{* *}$ & NS & NS & $0.21^{*}$ \\
\hline $\mathrm{IC} \%$ & & & & & & & & & $0.62^{\S}$ & $0.95^{\S}$ & $0.77 \S$ & NS \\
\hline IC/TLC & & & & & & & & & & $0.52^{\S}$ & $0.65^{\S}$ & $0.27^{*}$ \\
\hline IRV\% & & & & & & & & & & & $0.77 \S$ & NS \\
\hline IRV/TLC & & & & & & & & & & & & $0.21^{*}$ \\
\hline
\end{tabular}

1 TLC: total lung capacity, FRC: functional residual capacity, RV: residual volume, ERV: expiratory reserve volume, IC:

2 inspiratory capacity, IRV: inspiratory reserve volume, $\mathrm{D}_{\mathrm{L}} \mathrm{CO}$ : diffusing capacity for carbon monoxide. \%: \% predicted.

$3{ }^{\#}$ Spearman correlation coefficient, ${ }^{\S} \mathrm{p}<0.0001,{ }^{\dagger} \mathrm{p}<0.001,{ }^{* *} \mathrm{p}<0.01$, and ${ }^{*} \mathrm{p}<0.05$. NS $=$ non-significant. *Two of 94

4 participants missed lung volume measurements. 


\section{Table 4 (on next page)}

Pearson Correlations ( $r$ ) Pair-Wise Deletion between lung volumes and spirometry in participants with obstructive airway disease.

TLC: total lung capacity, FRC: functional residual capacity, RV: residual volume, ERV:

expiratory reserve volume, IC: inspiratory capacity, IRV: inspiratory reserve volume, $D_{L} C O$ : diffusing capacity for carbon monoxide, FVC: forced vital capacity, $\mathrm{FEV}_{1}$ : forced expired volume in one second, SVC: slow vital capacity. \%: \% predicted. "Spearman correlation coefficient, ${ }^{\S} p<0.0001,{ }^{\dagger} p<0.001,{ }^{* *} p<0.01$, and ${ }^{*} p<0.05 . n=94$ having spirometry, 92 having lung volume measurements, and 88 having $D_{L} C O$. 
1 Table 4. Pearson Correlations (r) Pair-Wise Deletion between lung volumes and spirometry in

2 participants with obstructive airway disease.

\begin{tabular}{|c|c|c|c|c|}
\hline & $\mathrm{FVC} \%$ & $\mathrm{FEV}_{1} \%$ & $\mathrm{FEV}_{1} / \mathrm{FVC}$ & $\mathrm{SVC} \%{ }^{\#}$ \\
\hline $\mathrm{FVC} \%$ & & $0.77 \S$ & 0.04 & $0.86^{\S}$ \\
\hline $\mathrm{FEV}_{1} \%$ & & & $0.63^{\S}$ & $0.62^{\S}$ \\
\hline $\mathrm{FEV}_{1} / \mathrm{FVC}$ & & & & -0.03 \\
\hline TLC\% $\%$ & $0.20 *$ & -0.11 & $-0.32^{* *}$ & $0.39^{\dagger}$ \\
\hline $\mathrm{FRC} \%$ & -0.09 & $-0.35^{\dagger}$ & $-0.36^{\dagger}$ & 0.09 \\
\hline FRC/TLC & $-0.33^{* *}$ & $-0.5^{\S}$ & $-0.36^{\dagger}$ & $-0.28^{* *}$ \\
\hline RV\% & $-0.29^{* *}$ & $-0.48^{\S}$ & $-0.35^{\dagger}$ & -0.2 \\
\hline RV/TLC & $-0.65^{\S}$ & $-0.67 \S$ & $-0.28^{* *}$ & $-0.67 \S$ \\
\hline ERV\% ${ }^{\#}$ & $0.43^{\S}$ & $0.27^{* *}$ & -0.07 & $0.58^{\S}$ \\
\hline ERV/TLC & $0.45^{\S}$ & $0.29^{* *}$ & -0.03 & $0.5^{\S}$ \\
\hline $\mathrm{IC} \%$ & $0.51^{\S}$ & $0.44 \S$ & 0.08 & $0.62 \S$ \\
\hline $\mathrm{IC} / \mathrm{TLC}$ & $0.32^{* *}$ & $0.49 \S$ & $0.36^{\dagger}$ & $0.25^{*}$ \\
\hline IRV\% & $0.5^{\S}$ & $0.37^{\dagger}$ & 0.01 & $0.63 \S$ \\
\hline IRV/TLC & $0.32^{* *}$ & $0.29^{* *}$ & 0.06 & $0.51^{\S}$ \\
\hline $\mathrm{D}_{\mathrm{L}} \mathrm{CO} \%$ & 0.19 & $0.34^{* *}$ & $0.29^{* *}$ & 0.18 \\
\hline
\end{tabular}

3 TLC: total lung capacity, FRC: functional residual capacity, RV: residual volume, ERV:

4 expiratory reserve volume, IC: inspiratory capacity, IRV: inspiratory reserve volume, $\mathrm{D}_{\mathrm{L}} \mathrm{CO}$ :

5 diffusing capacity for carbon monoxide, FVC: forced vital capacity, $\mathrm{FEV}_{1}$ : forced expired

6 volume in one second, SVC: slow vital capacity. \%: \% predicted. \#Spearman correlation

7 coefficient, ${ }^{\S} \mathrm{p}<0.0001,{ }^{\dagger} \mathrm{p}<0.001,{ }^{* *} \mathrm{p}<0.01$, and ${ }^{*} \mathrm{p}<0.05 . \mathrm{n}=94$ having spirometry, 92 having

8 lung volume measurements, and 88 having $\mathrm{D}_{\mathrm{L}} \mathrm{CO}$. 